\title{
NMR Isotope Tracking Reveals Cascade Steps in Carbohydrate Conversion by Sn-Beta
}

\author{
Elliot, Samuel Gilbert; Taarning, Esben; Madsen, Robert; Meier, Sebastian
}

Published in:

ChemCatChem

Link to article, DOI:

$10.1002 /$ cctc. 201701861

Publication date:

2017

Document Version

Peer reviewed version

Link back to DTU Orbit

Citation (APA):

Elliot, S. G., Taarning, E., Madsen, R., \& Meier, S. (2017). NMR Isotope Tracking Reveals Cascade Steps in Carbohydrate Conversion by Sn-Beta. ChemCatChem, 10(6), 1414-1419.

https://doi.org/10.1002/cctc.201701861

\section{General rights}

Copyright and moral rights for the publications made accessible in the public portal are retained by the authors and/or other copyright owners and it is a condition of accessing publications that users recognise and abide by the legal requirements associated with these rights.

- Users may download and print one copy of any publication from the public portal for the purpose of private study or research.

- You may not further distribute the material or use it for any profit-making activity or commercial gain

- You may freely distribute the URL identifying the publication in the public portal

If you believe that this document breaches copyright please contact us providing details, and we will remove access to the work immediately and investigate your claim. 


\section{NMR Isotope Tracking Reveals Cascade Steps in Carbohydrate Conversion by Sn-Beta}

\begin{abstract}
Quantitative isotope tracking studies were used to investigate the reaction pathways occurring for Sn-Beta catalyzed carbohydrate conversion to various alpha-hydroxy esters. Experimental insight into the conversion of pentoses was sought (i) by identifying pathways based on isotope patterns in the reaction products and (ii) through probing asymmetric isotope incorporation into products. The results indicate that reaction intermediates remain coordinated to the active site throughout the reaction cascades, regardless of the reaction pathway. A predominant transformation of the C1 carbohydrate position to the C3 position of methyl lactate resembles enzymatic glycolysis. Likewise, the majority of retro-aldol cleavage occurs from the carbohydrate in the ketose form, again resembling biological glycolysis. In addition, various side-activities are detected in Sn-Beta catalyzed carbohydrate conversion, including 5,1-hydride and 1,2carbon shift reaction of the carbohydrates.
\end{abstract}

Samuel G. Elliot, ${ }^{[\mathrm{a}]}$ Esben Taarning ${ }^{[\mathrm{b}]^{*}}$ Robert Madsen, ${ }^{[\mathrm{a}]}$ and Sebastian Meier ${ }^{[\mathrm{a}]^{*}}$

\section{Introduction}

The study of carbohydrates as alternative resources to petrochemicals has been intensifying in recent years. Despite this large interest, many routes of carbohydrate conversion to useful chemicals are complex and lack fundamental pathway understanding. The overall complexity of carbohydrate conversion in chemocatalytic pathways is reminiscent of the complexity encountered in biochemical pathways. Analytical methods that deal with challenging metabolic reaction systems are therefore conceivable additions to the toolbox of biomass research. Recently, we have shown that high-field NMR spectroscopy enables the identification, quantification and optimization of reactants at natural isotope enrichment in biomass conversion. ${ }^{[1]}$ In addition, NMR spectroscopy may provide additional mechanistic insight into reaction cascades through the characterization of isotope distributions in the products. $^{[2-8]}$ Herein, we focus on the Sn-Beta catalyzed conversion of abundant carbohydrates to methyl lactate (ML) and other alpha-hydroxy ester coproducts (Figure 1).

Production of lactate precursors for poly lactic acid production using tin-containing silicate chemocatalysis has been studied intensively since $2009 .^{[9]}$ Subsequent research has

[a] S. G. Elliot, Prof. R. Madsen, Dr. S. Meier Department of Chemistry

Technical University of Denmark

Kemitorvet, Bygning 207, 2800 Kgs. Lyngby, Denmark

E-mail: semei@kemi.dtu.dk

[b] Dr. E. Taarning

Haldor Topsøe A/S, Haldor Topsøes Alle 1, 2800 Kgs. Lyngby,

Denmark.

E-mail: esta@topsoe.com

Supporting information for this article is given via a link at the end of the document. illuminated some mechanistic details of the reactions forming methyl lactate (ML) from trioses and hexoses in methanol solvent. These developments resulted in increasingly feasible methods for tuning reaction selectivity, $\left.{ }^{[1,4}, 10-14\right]$ as well as discovery of new reaction products. ${ }^{[14-20]}$ Most of these new products are alpha-hydroxy acids like lactate and some show potential as polymer building blocks. ${ }^{[18,20-23]}$ These biomonomers include methyl 2,5,6-trihydroxy-3-hexenoate (THM), methyl 2,5-dihydroxy-3-pentenoate (DPM), methyl vinyl glycolate (MVG), assorted 3-deoxy esters (3DE) and lactones (3DL), the structures shown in Figure 1. Pathways leading to the formation of these compounds have so far remained less comprehensively studied than those of lactate formation, as these products were characterized more recently, and because the key $\mathrm{C}_{4}-\mathrm{C}_{6}$ intermediates are not as easily accessible in pure forms as analogous $\mathrm{C}_{3}$ compounds for use as reference standards and prospective reaction substrates.<smiles>COC(=O)C(C)O</smiles>

ML<smiles>C=CC(O)C(=O)OC</smiles>

MVG<smiles>COC(=O)C(O)/C=C/C(O)CO</smiles>
THM<smiles>[R]C(O)CC(O)C(=O)OC</smiles>

$3 \mathrm{DE}$<smiles>COC(=O)C(O)/C=C/CO</smiles>

DPM<smiles>[R]C1CC(O)C(=O)O1</smiles>

$3 \mathrm{DL}$
Figure 1. Product structures in the Sn-Beta catalyzed conversion of common carbohydrates, including methyl lactate (ML), methyl 2,5,6-trihydroxy-3hexenoate (THM), methyl 2,5-dihydroxy-3-pentenoate (DPM), methyl vinyl glycolate (MVG), assorted 3-deoxy esters (3DE) and lactones (3DL). The $\mathrm{R}$ group of $3 \mathrm{DE}$ and $3 \mathrm{DL}$ may be either $\mathrm{H}, \mathrm{CH}_{2} \mathrm{OH}$ or $\mathrm{CH}(\mathrm{OH}) \mathrm{CH}_{2} \mathrm{OH}$ for tetroses, pentoses or hexoses, respectively.

In the current study, we use various pentose isotopologues (pentoses with different isotope composition, i.e. different neutron content) to elucidate mechanistic details in the conversion of carbohydrates to alpha-hydroxy esters by Sn-Beta in methanol. We hypothesized that products and byproducts formed through the same pathway should be identifiable by similar isotope patterns. In addition, the formation of methyl lactate through retro-aldol cleavage of a carbohydrate to dihydroxyacetone or glyceraldehyde was reinvestigated. To this end, the symmetry of isotope incorporation was probed for products that might have arisen from symmetric dihydroxyacetone. Such experimental methods employing isotope tracking should have the prowess to identify consecutive steps in multistep-reaction pathways that occur in a concerted manner at the zeolite active sites. 


\section{Results and Discussion}

Initial experiments were conducted using $D-\left[1-{ }^{13} \mathrm{C}\right]$-xylose and uniformly ${ }^{2} \mathrm{H}$ labeled $\mathrm{D}$-[UL- $\left.{ }^{2} \mathrm{H}_{6}\right]$-ribose isotopologues (it has previously been demonstrated that the pentose stereochemistry does not affect reaction selectivity $\left.{ }^{[1]}\right)$. Pentoses were selected due to their inherently asymmetric aldol cleavage reactions that enable further distinction of product origins. Pentoses and hexoses have been found to produce an equivalent set of products $^{[1,14,19-20]}$ and it is therefore reasonable to assume that mechanistic findings for pentoses can be transferred to the mechanisms of hexose conversion and vice versa.

\section{Methyl Lactate}

The mechanism of methyl lactate formation from trioses has been studied previously for both homogeneous and heterogeneous tin systems. ${ }^{[3,9,24-26]}$ The mechanism is proposed to consist of the following five sequential steps: a) enolization, b) dehydration, c) tautomerization, d) (hemi)acetalization and e) hydride shift (Figure 2). The starting substrate may be either a ketose or aldose, as isomerization by a 1,2-intramolecular hydride shift will result in a mixture of both forms. Previous studies were conducted using protonated substrates in deuterated solvent and enolization was deduced from deuterium incorporation into the $\mathrm{C} 3$ position of $\mathrm{ML}^{[3]} \mathrm{A}$ detailed understanding of the occurring process was sought by sensitive detection and accurate quantification of hydrogen incorporation from the solvent. In addition, we sought to warrant that intramolecular hydride shifts can be distinguished from exchange with hydrogen atoms from the heterogeneous catalyst.

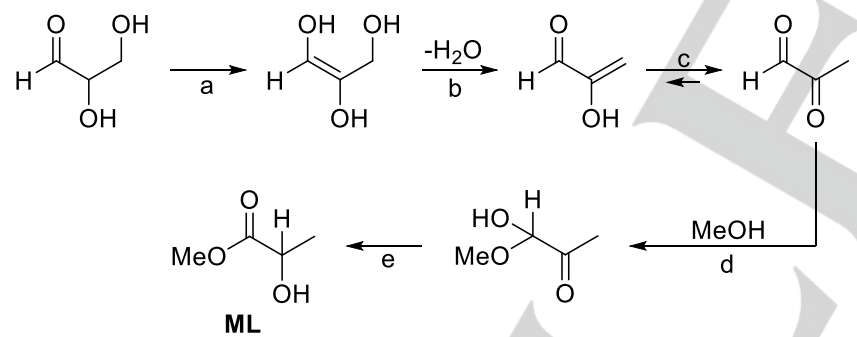

Figure 2. Plausible mechanism for the formation of lactate from trioses from the literature. ${ }^{[3,9,24-26]}$ Either dihydroxyacetone or glyceraldehyde may be employed as starting substrates.

We used deuterated pentose in protonated solvent to ensure that substrate and solvent as well as substrate and catalyst carried different isotopic forms of hydrogen. Resultant isotopologues of lactate were characterized by NMR spectroscopy at 18.7 Tesla magnetic field $(800 \mathrm{MHz}$ instrument equipped with cryogenically cooled detection electronics) using a previously demonstrated quantitative ${ }^{13} \mathrm{C}$ NMR (qNMR) approach. ${ }^{[1]}$ Deuterated carbon positions were identified from characteristic chemical shift changes to lower frequency and from characteristic multiplet patterns due to coupling to quadrupolar ${ }^{2} \mathrm{H}$ nuclei, as shown in Figure $3 \mathrm{~A} .{ }^{13} \mathrm{C}$ spectra were acquired with recycle delays of 60 seconds and using inversegated decoupling to avoid nuclear Overhauser enhancement of ${ }^{13} \mathrm{C}$ signal intensities for carbons bound to ${ }^{1} \mathrm{H}$.

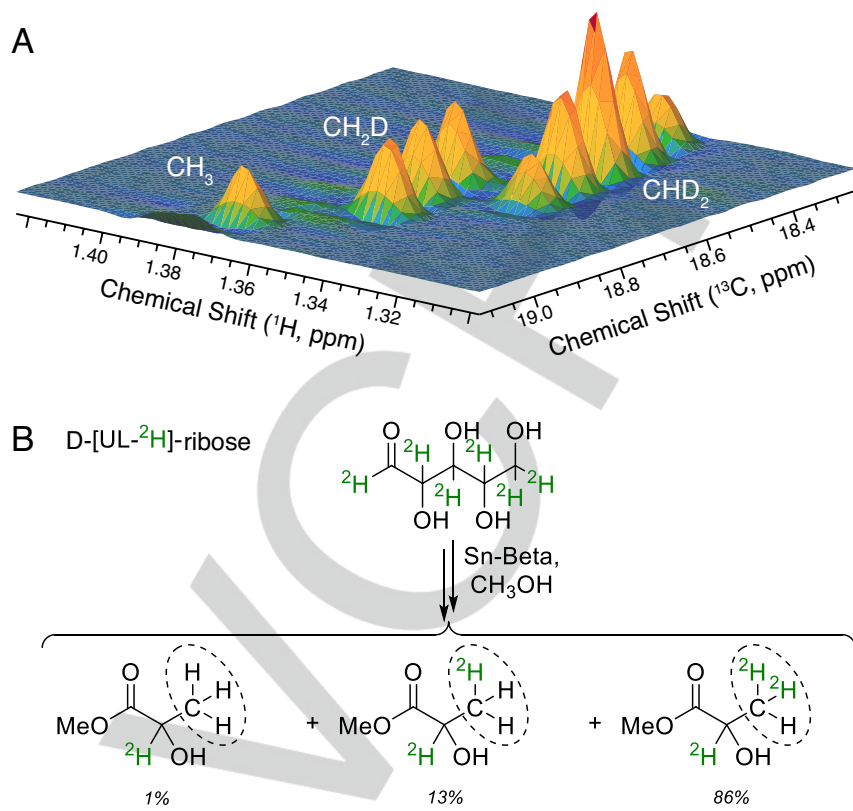

Figure 3. Multiplet pattern of the $\mathrm{C} 3$ position of $\mathrm{ML}$, resulting from incorporation of three, two and one ${ }^{1} \mathrm{H}$ atoms (from left to right), respectively (A). Fraction of lactate isotopomers produced upon reaction of D-[UL- $\left.{ }^{2} \mathrm{H}_{6}\right]$ ribose (B). Reactions consisted of $36 \mathrm{mg} D-\left[\mathrm{UL}^{2}{ }^{2} \mathrm{H}_{6}\right]$-ribose, $18 \mathrm{mg} \mathrm{Sn-Beta,}$ $500 \mu \mathrm{L}$ methanol and $5 \mathrm{mg}$ dimethyl sulfoxide (internal standard), which were heated to $160^{\circ} \mathrm{C}$ for $2 \mathrm{~h}$.

The resulting distribution of $\mathrm{ML}$ isotopologues from these experiments is shown in Figure 3B. Most notably, the lack of solvent exchange at the $\mathrm{C} 2$ position of lactate supports the hydride shift mechanism in step e (Figure 2) which must therefore be irreversible, as must the enolization in step a. The predominant isotopologue ( $86 \%$, Figure $3 \mathrm{~B}$ ) contains a single solvent proton at the $\mathrm{C} 3$ position, which is consistent with a reversible tautomerization in step c. The predominance of the singly C3 protonated isotopologue $(86 \%)$ over both the double $(13 \%)$ and triple $(1 \%)$ protonated forms indicate that reaction $\mathbf{d}$ is significantly faster than the competing reversible tautomerization in c.

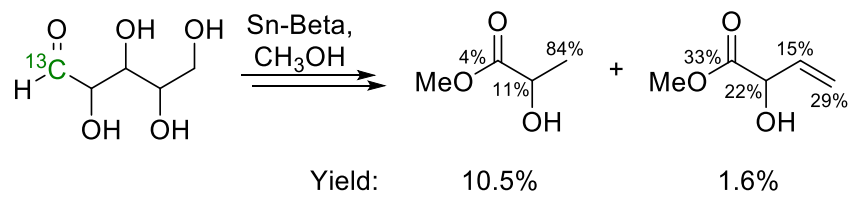

Figure 4. Distribution of ${ }^{13} \mathrm{C}$ in methyl lactate and methyl vinyl glycolate starting from $\mathrm{D}-\left[1-{ }^{13} \mathrm{C}\right]$-xylose. Reactions consisted of $36 \mathrm{mg} \mathrm{D}-\left[1-{ }^{13} \mathrm{C}\right]-x y l o s e$, $18 \mathrm{mg} \mathrm{Sn-Beta}, 500 \mu \mathrm{L}$ methanol and $5 \mathrm{mg}$ dimethyl sulfoxide (internal standard), which were heated to $160^{\circ} \mathrm{C}$ for $5 \mathrm{~min}$. Yields were determined by ${ }^{1} \mathrm{H}$-NMR and are given in mol\% carbon.

Subsequently, the reaction was repeated using $D-\left[1-{ }^{13} C\right]-$ xylose, resulting in ${ }^{13} \mathrm{C}$ distributions of $\mathrm{ML}$ and MVG shown in Figure 4. The prevalence of ${ }^{13} \mathrm{C}$ incorporation into the $\mathrm{C} 3$ position of $\mathrm{ML}$ shows that the $\mathrm{C} 3$ position of $\mathrm{ML}$ predominantly originates from the $\mathrm{C} 1$ position of the substrate. This observation was surprising as the formation of a $\mathrm{C} 3$ fragment containing the pentose $\mathrm{C} 1$ position could be expected to proceed from a freely formed triose, isomerizing between the aldose and ketose forms. Evidently, such a triose does not emerge in free form at 
noteworthy amounts, as it would imply a symmetric ${ }^{13} \mathrm{C}$ distribution in $\mathrm{ML}$ as well. We hypothesize that instead of a free triose, the retro-aldol cleavage of a ketose results in an enol covalently bonded to the tin-site, as displayed in Figure 5B. In this form, the primary alcohol arising from the $\mathrm{C} 1$ position of the carbohydrate substrate may coordinate and subsequently dehydrate. In this manner, the labeled carbon atom is now positioned in the $\mathrm{C} 3$ position of ML, Figure 5B. Notably, the conversion of the carbohydrate $\mathrm{C} 1$ position to the lactate $\mathrm{C} 3$ position is a common feature of chemocatalytic and biocatalytic glycolysis, resulting from coordination or phosphorylation of the carbohydrate $\mathrm{C} 1$ site, respectively. ${ }^{[27]}$

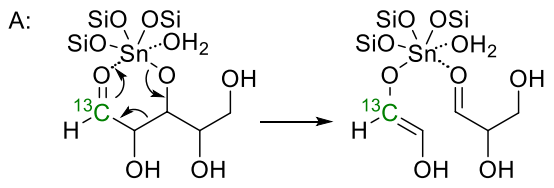

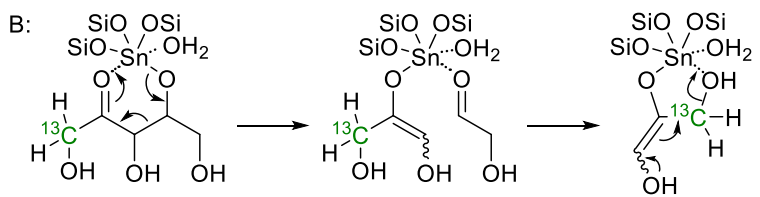

Figure 5. Plausible mechanism for retro-aldol cleavage of a $\left[1-{ }^{13} \mathrm{C}\right]-$ aldopentose (A) and a $\left[1{ }^{13} \mathrm{C}\right]$-ketopentose (B) to glycolaldehyde and glyceraldehyde.

Use of D-[1- $\left.{ }^{13} \mathrm{C}\right]$-xylose shows $84 \%$ of ${ }^{13} \mathrm{C}$ label at the $\mathrm{C} 3$ position of the ML formed, while, ${ }^{1} \mathrm{H}$ NMR shows $10.5 \%$ combined yield of all $\mathrm{ML}$ isotopomers and $7.4 \%$ yield of the ${ }^{13} \mathrm{C} 3$ labelled methyl-[3- $\left.{ }^{13} \mathrm{C}\right]$-lactate isotopomer, confirming that this isotopomer covers the majority of the methyl lactate formed (Figure S1). These distributions corroborate that the majority of methyl lactate appears to derive from the ketose form (Figure $5 \mathrm{~B}$ ) rather than the aldose (Figure $5 \mathrm{~A}$ ), even when an aldose is used as the substrate. Overall, isotope-tracking data thus suggest that the Sn-Beta catalyzed ML formation predominantly proceeds from the ketose form in a concerted manner where retro-aldol fragments remain bound to the active site. Similar isotope distributions with more than $80 \%$ of ${ }^{13} \mathrm{C}$ label at the $\mathrm{C} 3$ position of the ML formed are found for shorter (one minute) or longer ( 2 hours) reaction times.

Upon retro-aldol cleavage of a ketose or aldose to form ML, an equivalent amount of glycolaldehyde is formed, of which the majority must be unlabeled to correspond to the labeled ML formed. MVG may be formed from aldol condensation of two glycolaldehyde fragments. As expected, MVG was detected in the mixture and found to have a much more even distribution of ${ }^{13} \mathrm{C}$ than $\mathrm{ML}$, Figure $4 \mathrm{~B}$, with no predominant labeling at any single position.

\section{Methyl 2,5-dihydroxy-3-pentenoate}

Recently, it has become clear that various other alpha-hydroxy esters in addition to ML can be formed in significant amounts under similar catalytic conditions. The most abundant of these longer alpha-hydroxy esters formed from pentoses is methyl trans-2,5-dihydroxy-3-pentenoate (trans-DPM) which can be formed in yields above $30 \%$. trans-DPM and ML are five- and three-carbon alpha-hydroxy esters, respectively, and could be expected to follow similar mechanistic steps in the formation of the alpha-hydroxy ester functionality. The proposed mechanism for trans-DPM formation is expected to differ from that of ML shown in Figure 2, in step c. Here, tautomerization is replaced by an additional dehydration step, after which the pathway again can proceed equivalently to the reactions of step $\mathbf{d}$ and $\mathbf{e}$ for $\mathrm{ML}$. In order to investigate the mechanism for trans-DPM formation, we performed an analysis of trans-DPM using [UL- ${ }^{2} \mathrm{H}_{6}$ ] and [1${ }^{13} \mathrm{C}$ ] labelled pentoses equivalent to that performed for ML.

Experiments with the deuterated pentose showed less than $1 \%$ total solvent proton incorporation into trans-DPM, all of which was observed at the C5 position (Figure 6A). Most importantly, this finding excludes the significance of tautomerization to a free 3-deoxyxylosone type intermediate, as has been previously suggested, in the route to trans-DPM. ${ }^{[14,20]}$ The same lack of solvent exchange was observed in the pathway to furfural (Figure S2), showing that a 3-deoxyxylosone type intermediate was not part of the pathway for Sn-Beta catalyzed furfural formation.

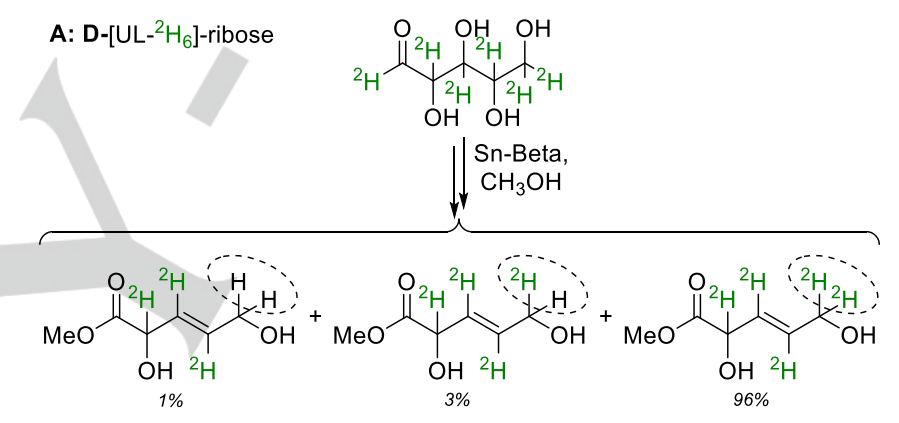

B: D-[1- $\left.{ }^{13} C_{1}\right]$-xylose

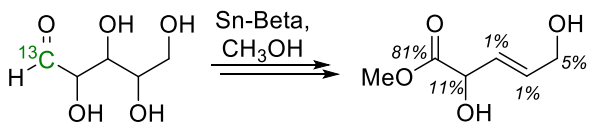

Figure 6. Amount of trans-DPM produced with the displayed isotopic configuration upon reaction of D-[UL- $\left.{ }^{2} \mathrm{H}_{6}\right]$-ribose (A). Distribution of ${ }^{13} \mathrm{C}$ in trans-DPM using D-[1- $\left.{ }^{13} \mathrm{C}\right]-x y l o s e(B)$. Reactions consisted of $36 \mathrm{mg}$ substrate, $18 \mathrm{mg} \mathrm{Sn}$-Beta, $500 \mu \mathrm{L}$ methanol and $5 \mathrm{mg}$ dimethyl sulfoxide (internal standard), which were heated to $160^{\circ} \mathrm{C}$ for $5 \mathrm{~min}$.

When using the $\left[1-{ }^{13} \mathrm{C}\right]$ pentose substrate, the ${ }^{13} \mathrm{C}$ isotope distributions show a peculiar pattern, Figure 6B. No scrambling of ${ }^{13} \mathrm{C}$ isotope into the $\mathrm{C} 3$ and $\mathrm{C} 4$ positions is observed and these positions retain close to the natural isotopic abundance of ${ }^{13} \mathrm{C}$. In addition, scrambling of ${ }^{13} \mathrm{C}$ isotope of $\left[1-{ }^{13} \mathrm{C}\right]$ pentose into the $\mathrm{C} 2$ and $\mathrm{C} 5$ positions is observed. Such a scrambling of ${ }^{13} \mathrm{C} 1$ to $\mathrm{C} 2$ and $\mathrm{C} 5$ is consistent with epimerization of the carbohydrate through a 1,2-carbon shift or isomerization by a 1,5-hydride shift, respectively. Previously, epimerization by 1,2carbon shifts had been reported for Sn-Beta at lower temperatures and 1,5-hydride shifts had been reported for other catalysts. ${ }^{[13,28-29]}$ In addition, trans-DPM is formed as the major isomer in all experiments with negligible formation of the cisisomer. The same selectivity is observed for both Sn-Beta and the homogeneous $\mathrm{SnCl}_{4}$, figure $\mathrm{S} 3$, thus excluding spatial confinement as the origin of cis-/trans-selectivity. 

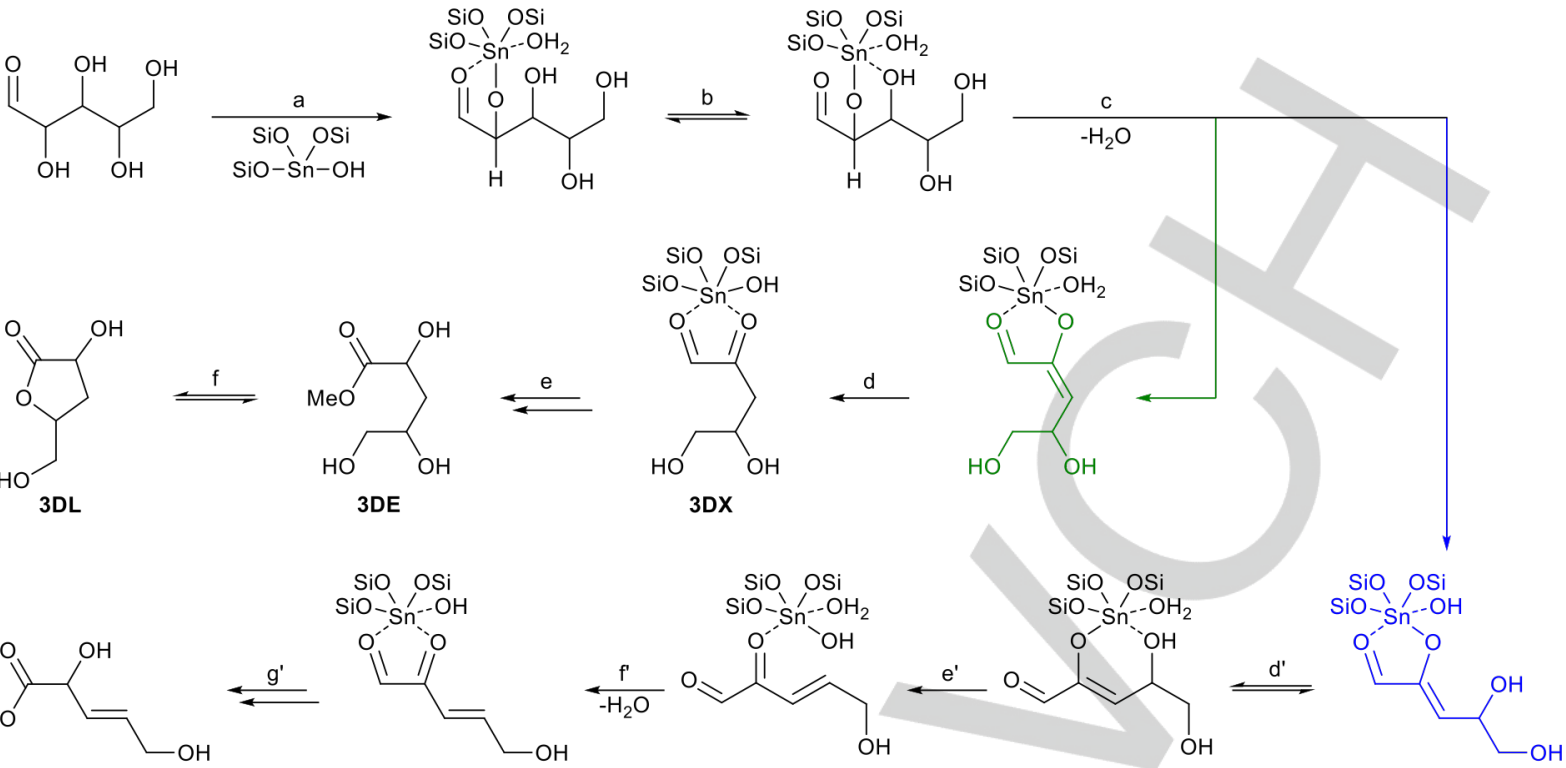

trans-DPM

Figure 7. Proposed mechanism for the formation of methyl trans-2,5-dihydroxy-3-pentenoate (trans-DPM), 3-deoxy- $\gamma$-xylonolactone (3DL) and methyl 3deoxy-xylonate $(3 D E)$ from $D$-xylose. The cis-precursor to step f' may also react by alternative pathways to form furfural in addition to the three products displayed.

Based on these observations a plausible reaction mechanism towards the formation of trans-DPM is shown in Figure 7 (blue). The C3 position of trans-DPM is maintained as a olefinic group throughout. Reversible keto-enol tautomerization of the $\mathrm{C} 3$ or $\mathrm{C} 4$ positions en route to trans-DPM can thus be excluded, as no solvent exchange is found at these positions. Formation of a trans C2-C3 bond in step c precludes cyclization and leads to a linear pathway forming trans-DPM, if a trans olefinic bond is formed in step e' as well. Formation of a cis olefinic bond in step e' may enable a cyclic dehydration pathway to furfural, supported by observed furfural isotopologues (Figure S2). Similar to the retro-aldol cleavage of ketose substrates (Figure 5), coordination at C2 elicits most central reaction chemistry in the pathway. Coordination at C2 is vital for hydride shifts in the equilibration of ketose and aldose substrates as well as the dehydration in steps $\mathbf{c}$ and $\mathbf{e}^{\text {'. }}$

Figure 7 accounts for the finding that experimentally observed products 3-deoxy- $y$-xylonolactone (3DL) and methyl 3deoxy-xylonate (3DE) derive from the same pathway (green), while trans-DPM derives from a different pathway, as witnessed from different patterns of isotope incorporation. Previous experiments identified 3-deoxyglycosone (the glucose analogue of 3DX) in reactions from glucose, and further experiments using a 3-deoxyglycosone substrate had indicated that this substrate predominantly forms saturated lactones and esters, thus supporting steps $\mathbf{e}$ and $\mathbf{f}^{[14]} \mathrm{A}$ rehydration of trans-DPM to $3 \mathrm{DE}$ seems unlikely as isolated trans-DPM does not react to 3DE under the current reaction conditions (Figure S4).

We hypothesize that the flux of intermediates into the two different pathways, for trans-DPM (and possibly furanics) as well as $3 D L / 3 D E$, may be influenced by the stereochemistry of step c Only the formation of a trans-2,3-enol favors subsequent 2,4 coordination and dehydration at C4. Formation of a cis-enol in step c of Figure 7 (green) will make the simultaneous coordination of the enol and the C4 hydroxyl group less favorable. In such a case tautomerization to the experimentally observed 3-deoxyxylosone intermediate (3DX) may occur in favor of dehydration, as shown in step $\mathbf{d}$, leading to formation the products $3 \mathrm{DL}$ and $3 \mathrm{DE}$ by intra- or intermolecular esterification, respectively. Experiments with the commercially available $\alpha$-hydroxy- $\gamma$-butyrolactone, showed that under the tested reaction conditions the lactone and the ester equilibrate (Figure S5), demonstrating that the products 3DL and 3DE and their formation is indistinguishable under the tested reaction conditions.

Considering the stereoselectivity for trans-DPM formation and previously reported stereoselectivity in the aldose-ketose isomerization by $\mathrm{C} 1-\mathrm{C} 2$ hydride shift, ${ }^{[30]}$ we set out to identify further stereoselective reactions in the pathways of Figure 7. Experiments with $\left[\mathrm{UL}^{2}{ }^{2} \mathrm{H}_{6}\right]$ aldopentose showed additional unanticipated isotope distributions in both $3 \mathrm{DL}$ and $3 \mathrm{DE}$. Stereoselectivity was observed for the 4 potential diastereomers of 3DL with isomerism at $\mathrm{C} 2$ and $\mathrm{C} 3$ (Figure 8). While stereoselectivity at the $\mathrm{C} 2$ position was low ( $9 \%$ diastereomeric excess (de) between xylono- and arabino-lactone forms), stereoselectivity for ${ }^{1} \mathrm{H}$ incorporation at the $\mathrm{C} 3$ position by tautomerization was $46 \% \pm 1 \%$ de for these two lactones. The same trend was observed for $3 \mathrm{DE}$ with $7 \%$ de for $\mathrm{C} 2$, and $46 \%$ de for both pairs of $\mathrm{C} 3$ diastereoisomers (Figure S6). The almost identical stereoselectivity at $\mathrm{C} 2$ and $\mathrm{C} 3$ in $3 \mathrm{DL}$ and $3 \mathrm{DE}$ is consistent with the two molecules arising from the same reaction pathway. The high diastereoselectivity of tautomerizations in this pathway and the high trans stereoselectivity in the dehydration pathway (Figure 7) parallel the high stereoselectivity in the hydride shifts of aldose-to-ketose isomerizations. Thus, Sn-Beta catalyzes a variety of stereoselective isomerization and dehydration reactions. 


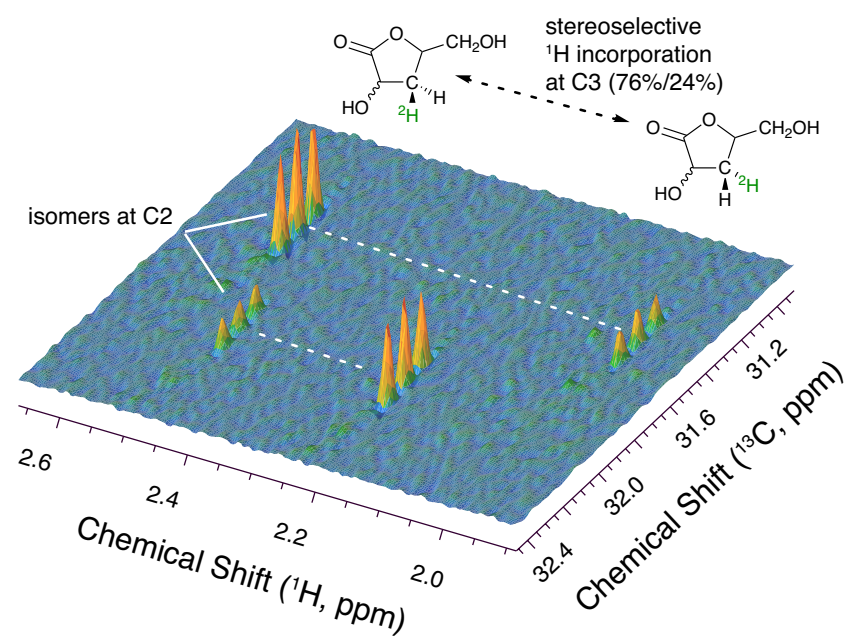

Figure 8. ${ }^{1} \mathrm{H}-{ }^{13} \mathrm{C}-\mathrm{HSQC}$ signals for the $\mathrm{C} 3$ position of $3 \mathrm{DL}$. The 4 potential diastereomer products (isomerism at $\mathrm{C} 2$ and $\mathrm{C} 3$ ) produced by reaction of enantiomerically pure [UL- ${ }^{2} \mathrm{H}_{6}$ ] pentose yield four triplets for $\mathrm{CH}$ groups at $\mathrm{C} 3$, as splitting by the quadrupolar ${ }^{2} \mathrm{H}$ was not decoupled.

\section{C5-C1 Hydride shift}

To elucidate the ability of Sn-Beta to perform a 5,1-hydride shift $\left[5,5^{\prime}-{ }^{2} \mathrm{H}_{2}\right]$-arabinose was selected for testing. Reaction of the $\left[5,5^{\prime}-{ }^{2} \mathrm{H}_{2}\right]$-arabinose showed a final distribution of $80 \%{ }^{2} \mathrm{H}_{2}$ and $20 \%{ }^{2} \mathrm{H}^{1} \mathrm{H}$ in the $\mathrm{C} 5$ position of trans-DPM (Figure 9). Compared with the lower $(<4 \%)$ proton incorporation in the uniformly deuterated substrate (Figure 6A) under identical reaction conditions, this finding indicates that intramolecular hydride exchange is taking place. A $\mathrm{C} 5-\mathrm{C} 1$ hydride shift as previously detected in titanium-Beta catalyzed reactions is the most plausible explanation. ${ }^{[29]}$ Analysis of the distribution of ${ }^{2} \mathrm{H}$ in $\mathrm{ML}$ from $\left[5,5^{\prime}-{ }^{2} \mathrm{H}_{2}\right]$-arabinose showed that the $\mathrm{C} 3$ position had $78 \%$ ${ }^{1} \mathrm{H}_{3}$ and $22 \%{ }^{2} \mathrm{H}^{1} \mathrm{H}_{2}$ (Figure S7). This incorporation correlates to migration of the label from the $\mathrm{C} 5$ position to the $\mathrm{C} 1$ as detected from the isotope pattern in trans-DPM after a hydride shift for approximately $20 \%$ of the molecules (Figure 9). Thus, use of a $\left[5,5^{\prime}-{ }^{2} \mathrm{H}_{2}\right]$ labelled pentose underlines that $\mathrm{ML}$ primarily originates from the ketose as shown in Figure 5. In addition, the results indicate that a $\mathrm{C} 5-\mathrm{C} 1$ hydride shift occurs in the carbohydrate form, but only for a minority of the substrate carbohydrate.

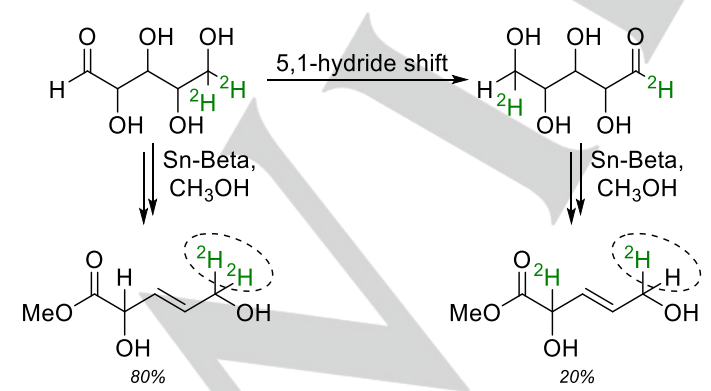

Figure 9. Amount of trans-DPM produced with the displayed isotopic configurations upon reaction of a $\left[5,5^{\prime}-{ }^{2} \mathrm{H}_{2}\right]$-arabinose. Reactions consisted of $36 \mathrm{mg}$ substrate, $18 \mathrm{mg} \mathrm{Sn-Beta,} 500 \mu \mathrm{L}$ methanol and $5 \mathrm{mg}$ dimethyl sulfoxide, which were heated to $160^{\circ} \mathrm{C}$ for $5 \mathrm{~min}$.

\section{Conclusion}

In conclusion, we employ isotope labeled substrates to track isotope redistribution and solvent exchange in varying products formed during chemocatalytic carbohydrate conversion. The experiments have shown that ketoses are the primary substrates for retro-aldol cleavage much like enzymatic glycolysis. This finding is consistent with a rapid hydride-shift between aldose and ketose under reaction conditions of alpha-hydroxy ester formation $\left(\sim 160^{\circ} \mathrm{C}\right)$. Furthermore, a strong binding is observed between substrate and catalyst, resulting in regioselective formation of methyl lactate, occurring through irreversible formation of an enol, which continues in a cascade reaction through to methyl lactate. Analogous conclusions can be drawn for pathways that do not encompass a retro-aldol step. Also here, experimental data is consistent with a strong coordination of the enol form by the catalyst active site. These pathways include enols formed in the cascade toward trans-DPM, 3DL, 3DE and similar 3-deoxy esters which exhibit little isotope scrambling once the reaction cascade commences. However, our experiments show some atom rearrangement attributed to reactions with unconverted carbohydrates. Sn-Beta was shown to catalyze a 5,1-hydride shift of carbohydrates, as well as previously reported 1,2-hydride shift and a Bilik-type 1,2-carbon shift. We thus find that rich mechanistic information can be derived by use of quantitative isotope-tracking experiments in complex reaction mixtures formed in biomass conversion.

\section{Experimental Section}

D- $\left[1-{ }^{13} \mathrm{C}\right]$-xylose $\left(99 \%\right.$ atom- $\left.\%{ }^{13} \mathrm{C}\right)$ was obtained from SigmaAldrich. D-[UL- $\left.{ }^{2} \mathrm{H}_{6}\right]$ and D-[5,5'- $\left.{ }^{2} \mathrm{H}_{2}\right]$-arabinose $\left(98 \%\right.$ atom- $\left.\%{ }^{2} \mathrm{H}\right)$ were obtained from Omicron Chemicals. Reactions were conducted with a Biotage Initiator ${ }^{+}$microwave reactor in $500 \mu \mathrm{L}$ glass reaction vials. Reactions were typically conducted with 18 $\mathrm{mg}$ Sn-Beta (Si/Sn $=200$, hydrothermally synthesized), $36 \mathrm{mg}$ substrate, $500 \mu \mathrm{L}$ methanol and $5 \mathrm{mg}$ dimethyl sulfoxide as an internal standard.

The Sn-Beta catalyst was hydrothermally synthesized in accordance with the procedure by Tolborg et al, employing a target $\mathrm{Si} / \mathrm{Sn}$ ratio of $200 .^{[31]}$ The catalyst structure and composition was confirmed by ICP-OES $(0.9 \mathrm{wt} \% \mathrm{Sn}, \mathrm{Si} / \mathrm{Sn}=$ 196), XRD ( ${ }^{*} B E A$ framework) and $\mathrm{N}_{2}$ absorption ( $\mathrm{S}_{\mathrm{BET}}=540 \mathrm{~m}^{2}$ $\mathrm{g}^{-1}, \mathrm{~S}_{\text {micropore }}=436 \mathrm{~m}^{2} \mathrm{~g}^{-1}, \mathrm{~V}_{\text {total }}=0.30 \mathrm{~mL} \mathrm{~g}^{-1}, \mathrm{~V}_{\text {micropore }}=0.22 \mathrm{~mL}$ $\mathrm{g}^{-1}$ calculated by the $t$-plot method).

NMR isotope tracking was performed using spectra that were acquired on an $800 \mathrm{MHz}$ Bruker Avance III NMR spectrometer equipped with a $\mathrm{TCl}$ CryoProbe and a SampleJet sample handler. Data were zero-filled to double the number of the acquired complex data points prior to Fourier transformation in all spectral dimensions using Bruker Topspin $3.5 \mathrm{pl} 7$ software. Quantifications were obtained from qNMR experiments without pulse sequence elements that enhance or suppress signal, but with extensive inter-scan recycle delays. Two-dimensional ${ }^{1} \mathrm{H}$ ${ }^{13} \mathrm{C}$ NMR HSQC spectra validated the assignment of the integrated $1 \mathrm{D}{ }^{13} \mathrm{C}$ spectra. Incorporation of deuterium was verified from chemical shift changes and multiplet patterns in 
HSQC spectra, where spectral editing was used to distinguish carbon sites by the number of attached protons (and hence incorporated deuterons; see Figures 3 and 8). Quantitative proton decoupled ${ }^{13} \mathrm{C} 1 \mathrm{D}$ spectra were acquired with recycle delays of 60 seconds using a pulse sequence that employs inverse gated decoupling to avoid nuclear Overhauser enhancement of protonated sites.

\section{Acknowledgements}

This work was funded by the Innovation Fund Denmark (case number 5150-00023B). $800 \mathrm{MHz}$ NMR spectra were recorded on the spectrometer of the NMR center DTU supported by the Villum foundation. We gratefully acknowledge Dr. Søren Tolborg (Haldor Topsøe AS) for his expertise and work in synthesizing the employed Sn-Beta catalyst.

Keywords: alpha-hydroxy esters $\cdot$ carbohydrates • heterogeneous catalysis $\cdot$ NMR spectroscopy $\bullet$ reaction mechanisms

\section{References}

[1] S. G. Elliot, S. Tolborg, I. Sádaba, E. Taarning, S. Meier ChemSusChem 2017, 10, 2990-2996.

[2] R. Bermejo-Deval, M. Orazov, R. Gounder, S.-J. Hwang, M. E. Davis, ACS Catal. 2014, 4, 2288-2297.

[3] P. P. Pescarmona, K. P. Janssen, C. Delaet, C. Stroobants, K. Houthoofd, A. Philippaerts, C. De Jonghe, J. S. Paul, P. A. Jacobs, B. F. Sels, Green Chem. 2010, 12, 1083-1089.

[4] R. Bermejo-Deval, R. S. Assary, E. Nikolla, M. Moliner, Y. RománLeshkov, S.-J. Hwang, A. Palsdottira, D. Silverman, R. F. Lobo, L. A. Curtiss, M. E. Davis, Proc. Natl. Acad. Sci. U. S. A. 2012, 109, 97279732.

[5] S. Van de Vyver, C. Odermatt, K. Romero, T. Prasomsri, Y. RománLeshkov, ACS Catal. 2015, 5, 972-977.

[6] T. R. Carlson, J. Jae, G. W. Huber, ChemCatChem 2009, 1, 107-110.

[7] M. Foston, R. Samuel, A. J. Ragauskas, Analyst 2012, 137, 3904-3909.

[8] H. Ben, G. A. Ferguson, W. Mu, Y. Pu, F. Huang, M. Jarvis, M. Biddy, Y. Deng, A. J. Ragauskas, Phys. Chem. Chem. Phys. 2013, 15, 1913819142.

[9] E. Taarning, S. Saravanamurugan, M. S. Holm, J. Xiong, R. M. West, C. H. Christensen, ChemSusChem 2009, 2, 625-627.

[10] M. S. Holm, S. Saravanamurugan, E. Taarning, Science 2010, 328, 602-605.
[11] M. Moliner, Y. Román-Leshkov, M. E. Davis, Proc. Natl. Acad. Sci. U. S. A. 2010, 107, 6164-6168.

[12] Y. Román - Leshkov, M. Moliner, J. A. Labinger, M. E. Davis, Angew. Chem. Int. Ed. 2010, 49, 8954-8957; Angew. Chem. 2010, 122, 91389141

[13] W. R. Gunther, Y. Wang, Y. Ji, V. K. Michaelis, S. T. Hunt, R. G. Griffin, Y. Román-Leshkov, Nat. Commun. 2012, 3, 1109.

[14] S. Tolborg, S. Meier, I. Sádaba, S. G. Elliot, S. K. Kristensen, S. Saravanamurugan, A. Riisager, P. Fristrup, T. Skrydstrup, E. Taarning, Green Chem. 2016, 18, 3360-3369.

[15] T. Usui, S. Yanagisawa, M. Onguchi, M. Yoshino, R. Kawabata, J. Kishimoto, Y. Arai, K. Aida, H. Watanabe, F. Hayase, Biosci. Biotechnol. Biochem. 2007, 71, 2465-2472.

[16] M. S. Holm, Y. J. Pagán-Torres, S. Saravanamurugan, A. Riisager, J. A. Dumesic, E. Taarning, Green Chem. 2012, 14, 702-706.

[17] M. Dusselier, P. Van Wouwe, F. de Clippel, J. Dijkmans, D. W. Gammon, B. F. Sels, ChemCatChem 2013, 5, 569-575.

[18] M. Dusselier, P. Van Wouwe, S. De Smet, R. De Clercq, L. Verbelen, P. Van Puyvelde, F. E. Du Prez, B. F. Sels, ACS Catalysis 2013, 3, 17861800.

[19] H. S. Chen, A. Wang, H. Sorek, J. D. Lewis, Y. Román - Leshkov, A. Bell, ChemistrySelect 2016, 1, 4167-4172.

[20] S. G. Elliot, C. Andersen, S. Tolborg, S. Meier, I. Sadaba, A. E. Daugaard, E. Taarning, RSC Adv. 2017, 7, 985-996.

[21] K. Madhavan Nampoothiri, N. R. Nair, R. P. John, Bioresour. Technol. 2010, 101, 8493-8501.

[22] E. Castro-Aguirre, F. Iñiguez-Franco, H. Samsudin, X. Fang, R. Auras, Adv. Drug Deliv. Rev. 2016, 107, 333-366.

[23] O. Dechy-Cabaret, B. Martin-Vaca, D. Bourissou, Chemical Reviews 2004, 104, 6147-6176.

[24] Y. Hayashi, Y. Sasaki, Chem. Commun. 2005, 21, 2716-2718.

[25] P. N. R. Vennestrøm, C. M. Osmundsen, C. H. Christensen, E. Taarning, Angew. Chem. Int. Ed. 2011, 50, 10502-10509; Angew. Chem. 2011, 123, 10686-10694.

[26] L. Li, C. Stroobants, K. Lin, P. A. Jacobs, B. F. Sels, P. P. Pescarmona, Green Chem. 2011, 13, 1175-1181.

[27] A. Bar-Even, A. Flamholz, E. Noor, R. Milo, Nat. Chem. Biol. 2012, 8, 509-517.

[28] M. E. Davis, R. Gounder, C. I. O. Technology, US, 2014.

[29] R. Gounder, M. E. Davis, ACS Catal. 2013, 3, 1469-1476.

[30] S. Saravanamurugan, A. Riisager, E. Taarning, S. Meier, Chem. Commun. 2016, 52, 12773-12776.

[31] S. Tolborg, A. Katerinopoulou, D. D. Falcone, I. Sádaba, C. M. Osmundsen, R. J. Davis, E. Taarning, P. Fristrup, M. S. Holm, J. Mater. Chem. A 2014, 2, 20252-20262. 
Entry for the Table of Contents (Please choose one layout)

Layout 2:

\section{FULL PAPER}

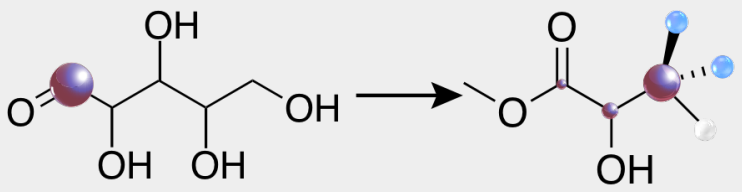

Pathfinder: Reaction pathways in biomass valorisation often remain enigmatic. Carbohydrates with different isotope composition (different neutron content) were used to elucidate mechanistic details in the chemocatalytic conversion of carbohydrates by Sn-Beta. Results indicate strong coordination of reaction intermediates and mechanistic similarities to enzymatic glycolysis.
Samuel G. Elliot, Esben Taarning, * Robert Madsen, and Sebastian Meier*

Page No. - Page No.

NMR Isotope Tracking Reveals Cascade Steps in Carbohydrate Conversion by Sn-Beta 